\title{
TABELANDO: OBJETO DE APRENDIZAGEM PARA LETRAMENTO ESTATÍSTICO
}

\author{
EDSON DO CARMO, GILVANDENYS LEITE SALES, \\ Michelle Guerreiro CaCAis, Adaias Gomes \\ Instituto Federal de Educação, Ciência e Tecnologia do Ceará (IFCE) \\ Campus de Fortaleza \\ Programa de Pós-graduação em Ensino de Ciências e Matemática (PPGECM) \\ $<$ carmoedson@yahoo.com.br>. <denyssales@gmail.com> \\ $<$ michellecacais@gmail.com>.<adaiasgomes314@gmail.com>
}

DOI: 10.21439/conexoes.v10i4.1089

\begin{abstract}
Resumo. No ensino de Matemática, em especial na área de Estatística, existem muitas deficiências, que vão desde a dificuldade em assimilar fórmulas, interpretar gráficos, solucionar problemas até à compreensão de dados estatísticos. Essa constatação evidencia a necessidade da utilização dos avanços tecnológicos associados às novas práticas pedagógicas. Tendo em vista essas dificuldades e tomando por base as recomendações presentes nos Parâmetros Curriculares Nacionais (PCN), propõe-se pôr em prática os princípios progressistas da educação através do Objeto de Aprendizagem (OA) "Tabelando". Este foi desenvolvido para facilitar a aquisição de conhecimentos específicos e do tópico Distribuição de Frequência com Intervalo de Classe para turmas de Ensino Médio. A metodologia de pesquisa inicia-se com um apanhado teórico em torno do assunto Estatística, aprendizagem significativa e sobre a utilização de OA para o estudo matemático; a seguir, foi concebido, desenvolvido, implementado e avaliado o OA Tabelando; por fim, um questionário de avaliação didático-pedagógico foi aplicado em turmas para verificar seu desempenho e saber do grau de satisfação do usuário. Com base nos dados coletados espera-se obter como resultado dados esclarecedores sobre a real intervenção e contribuição que o OA proposto possa trazer ao ser utilizado em sala de aula.
\end{abstract}

Palavras-chaves: Ensino de Matemática e de Estatística. Aprendizagem significativa. Letramento estatístico. Objeto de Aprendizagem.

\begin{abstract}
In the teaching process of Mathematics, mainly in the field of Statistics, there are many flaws, which go from the difficulty on learning formulas, reading graphs and solving problems until understanding statistical data. Thus, to use digital learning mechanisms can enable satisfactory experiences in the learning process. considering the difficulties encountered in the classroom, and based on the recommendations and orientations present in the "Parâmetros Curriculares Nacionais (PCN)", this research proposes the Learning Object (LO) TABELANDO. This was developed to facilitate the specific instruction of the topic Frequency Distribution with Class Interval for high school classes. The methodology of this research starts with a theoretical study around the field of Statistics, significant learning and the utilization of LO on the learning process of Mathematics; hereafter, the design, development, implementation and evaluation of the LO TABELANDO; finally, an evaluation didactic-pedagogic survey focusing also on the ergonomic was applied in each class to verify its performance to know the level of satisfaction of the user. Based on the data collected it is expected to obtain as results clarifying data about the actual intervention and contribution that the LO proposed is able to cause once it is applied in a classroom.
\end{abstract}

Keywords: Mathematics and Statistics instruction. Significant learning. Statistics literacy. Learning Object. 


\section{INTRODUÇÃO}

São notáveis as transformações socioeconômicas pelas quais passam as nações do mundo atual e, por conseguinte, as pessoas, seus hábitos e estilo de vida.Para que os estudantes acompanhem essas importantes mudanças e possam tirar um bom proveito delas, torna-se necessária a atualização dos currículos escolares, que devem contribuir para a inserção do jovem no mundo das novas tecnologias.

Nos últimos anos, as TDIC (Tecnologias Digitais da Informação e Comunicação) têm se convertido em relevantes ferramentas no aprimoramento da aprendizagem, através do desenvolvimento de softwares educativos, com resultados satisfatórios no desenvolvimento das potencialidades dos alunos, a exemplo da interpretação de gráficos ou resolução de cálculos mais complexos.

Durante um longo período de tempo, o ensino da Estatística resumiu-se à decoração de fórmulas matemáticas e conceitos estatísticos, bem de acordo com a aprendizagem memorística. A motivação deste trabalho está no Letramento Estatístico para acrescentar elementos atuais no ensino tradicional dessa disciplina, e colocar em prática os princípios progressistas da Educação, por meio de uma ferramenta tecnológica cada vez mais presente em sala de aula: o computador e suas ferramentas.

O Objeto de Aprendizagem (OA) Tabelando é uma ferramenta para auxiliar no ensino de Distribuição de Frequência com intervalos, baseado no modelo de desenvolvimento de objetos de aprendizagem, desenvolvido por Sales (2012). Consiste em um artefato para plataforma web, podendo ser acessado por qualquer dispositivo com acesso à internet.

A partir dos pressupostos ora elencados e visando o devido Letramento Estatístico, foco principal deste trabalho, o objetivo desta pesquisa é desenvolver o Objeto de Aprendizagem Tabelando para o apoio ao ensino e aprendizagem de Estatística e de seus conceitos, com proposta didática voltada a auxiliar o aluno na interpretação de tabelas estatísticas, aplicando-as em cenários reais de seu mundo vivencial.

Espera-se que este instrumento gere interação, participação entre os estudantes, que facilite a aprendizagem coletiva e, com isso, também possa dinamizar as aulas e promover uma experiência pedagógica bem mais produtiva, de forma que os alunos saibam, além de interpretar os dados estatísticos, utilizá-los como ferramenta de conhecimento da realidade social.

\section{FUNDAMENTAÇÃO TEÓRICA}

No ano de 1996, houve uma mudança no ensino do Brasil, quando foi proposta a nova LDB - Lei de Diretrizes e Bases da Educação - lei no 9394 de 20/12/1996 (BRASIL, 1996). A LDB trata de todas as orientações e tendências a serem seguidas e aplicadas, abrangendo desde o ensino infantil ao ensino superior. A seção 4 da respectiva lei trata especificamente das diretrizes curriculares para o Ensino Médio. Quanto à disposição curricular, a Lei 9.394/96 está em consonância e traz as fundamentações inseridas pelas Diretrizes Curriculares Nacionais para o Ensino Médio - DCNEM (BRASIL, 1998) complementando as recomendações dos Parâmetros Curriculares Nacionais do Ensino Médio (BRIGNOL, 2004), porém atualmente a sociedade passou por mudanças rápidas e isso influenciou completamente na forma de aprender.

Em um contexto educacional como este, onde há constantes modificações e avanços tecnológicos, emergem mudanças nos conteúdos propostos e na formação do aluno. Como bem cita o art. $6^{\circ}$ dos PCN: “[...] Os princípios pedagógicos da identidade, diversidade e autonomia, da interdisciplinaridade e contextualização são adotados como estruturadores dos currículos" (BRASIL, 1998).

Para Brignol (2004, p.16), o uso de recursos didáticos e de ambientes digitais, podem ser empregados para proporcionar um ensino e aprendizagem diferenciados e modifica também a forma de como são tratadas as informações adquiridas nesse processo. Afinal, os PCN referentes ao ensino da Matemática e da Estatística, determinam os eixos fundamentais para compor um leque de integração e tratar da melhor forma possível a coleta e análise de informações, incluem-se aqui as noções de Estatística, Probabilidade e Análise Combinatória (BRASIL, 1997).

O Letramento Estatístico é atualmente um dos maiores desafios do ensino das disciplinas de Matemática e Estatística. Essa necessidade primeiramente decorre da tentativa de se adequar a didática de ensino dessas disciplinas às diretrizes dos Parâmetros Curriculares Nacionais $(\mathrm{PCN})$, no tocante às competências a serem desenvolvidas nos alunos.

Soares (2002) associa o termo letramento ao uso e apropriação da leitura e da escrita diante das demandas sociais e profissionais. Atos de letramento estão tão presentes no cotidiano que são até imperceptíveis: a leitura de livros, jornais, revistas, a escrita de cartas, e-mails, mensagens em redes sociais, nas informações em uma conta de luz, em bulas de remédios, em receitas, etc.

Uma pessoa não letrada sofre constantes problemas 
e frustrações em seu cotidiano, a exemplos da incapacidade que algumas pessoas têm de identificar lugares, pegar ônibus, ler e escrever documentos, entre outros. Gal (2002 apud ALMEIDA, 2010, p.12) afirma que "um adulto letrado consegue entender fenômenos e tendências de relevância cultural, social e pessoal, e possibilita a abertura para o indivíduo se posicionar criticamente frente a informações".

De acordo com Gal (2004 apud ALMEIDA, 2010), o Letramento Estatístico possibilita mudanças comportamentais, impulsiona a busca por informações, e permite a compreensão de conceitos complexos como os voltados para a área das Ciências Exatas. Permite também a compreensão de dados e informações estatísticas, pesquisas e números apontados constantemente em revistas, jornais e telejornais.

Almeida (2010), Cazorla e Santana (2010) em seus estudos demonstram um modelo de Letramento Estatístico proposto por Gal (2002 apud ALMEIDA, 2010), onde define dois componentes fundamentais: o cognitivo e o afetivo. O modelo cognitivo possui elementos responsáveis pela competência das pessoas para compreender, interpretar e avaliar criticamente as informações estatísticas. Já o afetivo possui dois elementos de disposição, o primeiro diz respeito a atitudes e crenças das pessoas, já o segundo tem a ver com a postura crítica que moldam suas visões de mundo, identificam posturas críticas que nada mais são do que a propensão para um posicionamento questionador e indagador diante das informações estatísticas.

Rumsey (2002 apud ALMEIDA, 2010, p.22) apresenta uma proposta de assuntos fundamentais para serem abordados na disciplina de Estatística, para desenvolver o que ela chama de "competência estatística e cidadania estatística". Esses pontos podem contribuir nos processos de Letramento Estatístico dos alunos e também beneficiam no desenvolvimento das habilidades científicas e de pesquisa, como cita Almeida:

Conhecimentos de dados; Entendimento sobre a terminologia e conceitos básicos de estatísticas; Compreensão dos procedimentos para coleta de dados e geração de estatísticas descritivas; Habilidades básicas de interpretação (habilidade para descrever o que os resultados significam no contexto do problema); Habilidades básicas de comunicação (ser capaz de explanar os resultados para outras pessoas) Rumsey (2002 apud ALMEIDA, 2010 p.22-23).

Com base nessa proposta o professor passa a ter em mãos um mecanismo essencial para desenvolver o material significativo de ensino de Estatística, e assim acompanhar de perto o progresso do aluno, traçando estratégias de ensino mais eficazes e capazes de compreender o grau de dificuldade que aquele aluno possui, como trabalhar essa dificuldade, quais as habilidades o aluno já adquiriu, e qual a potencialidade do mesmo em externar o conhecimento que obteve.

O Objeto de Aprendizagem tem impacto no ensino de Estatística, sendo importante no processo de construção do conhecimento no atual cenário de crescente utilização dos recursos educacionais digitais em sala de aula.Compreendem-se objetos de aprendizagem digitais de forma específica, pois o significado para o termo objetos de aprendizagem é algo mais amplo, sendo necessário conhecer esse significado e os autores que definiram de forma macro.

Hoffman (2007 apud SILVA; CAFÉ; CATAPAN, 2011) faz referências à literatura na qual identificou divergências nos significados de OA, mas afirmam que um OA pode ser qualquer coisa com objetivo educacional que possa ser utilizado para estruturar uma aula ou facilitar o processo de aprendizagem.

Corroborando com as ideias de Hoffman (2007) apud SILVA; CAFÉ; CATAPAN, 2011) colocam os OA como objetos educacionais físicos, sendo objetos normais e comuns, como um livro, uma árvore, um céu estrelado, uma calculadora, ou materiais digitais como documentos, ou outros arquivos digitais como textos, imagens e vídeos desde que todos possam ser utilizados para promover a aprendizagem.

De acordo com o Institute of Eletrictaland Eletronics Engineers (IEEE) o significado de Objeto de Aprendizagem de forma mais branda é "qualquer entidade, digital ou não digital, que possa ser usada, reutilizada ou referenciada durante o uso de tecnologias que suportem o ensino" (IEEE, 2002). Essa definição do IEEE coloca de forma mais ampla o significado de OA, diferenciando os objetos digitais e não digitais, e o que é mais destacável, a colocação de ser reutilizável, ou seja, podem ser utilizados quantas vezes forem necessárias para aprender o assunto abordado, e referenciado quanto ao assunto tratado em aula.

Os diferentes recursos computacionais voltados para a aprendizagem são desenvolvidos a fim de prover uma aprendizagem significativa, desenvolvendo um contexto de aprendizagem mais dinâmico e motivador. (VYGOTSKY, 1984), em seus estudos, aponta a aprendizagem como sendo uma passagem de níveis o que ela chama de ZDP (Zona de Desenvolvimento Proximal) onde o aprendiz passa de um estado em que pode realizar uma atividade sozinho (nível real), para um estágio que caminha com a ajuda do outro mais capaz ou de 
algo, como um OA, que o auxilie a transpor barreiras até atingir um novo nível (nível potencial).

O software educacional deve provê ferramentas que desenvolvam as capacidades cognitivas, e possibilite uma evolução na aprendizagem. É importante que este proporcione uma aprendizagem significativa, para que não venha a ser apenas um ambiente computacional nos mesmos moldes de uma visão tradicional/instrucionista. Também precisa ser um ambiente e/ou ferramenta que desafie, provoque e estimule o aluno a pensar, ao levantar questionamentos, instigar e gerar conflitos.

\section{ESPECIFICAÇÕES DO OA TABELANDO}

Para a elaboração do OA Tabelando foi utilizada como base a metodologia para desenvolvimento de Objetos de Aprendizagem proposta pelo RIVED (Rede Interativa Virtual de Educação), devidamente adaptada por Sales (2012), que demonstra as etapas para a elaboração do OA, consistindo em três fases essenciais, como pode ser visto na Figura 1 .

A primeira fase é a fase de concepção e criação do Design Pedagógico Instrucional. Nela os principais atores realizarão a ideia de criação do OA, além de especificar quais os conteúdos abordados. Aqui são necessários três personagens: Os especialistas em conteúdo os quais são responsáveis por planejar, analisar e especificar qual o assunto o OA abordará; os técnicos em educação, que são responsáveis por intermediar os conteúdos produzidos pelos especialistas e transpor este conteúdo de forma mais prática para o designer instrucional, e este último, que tratará o conteúdo de forma mais técnica e modelará o esqueleto do OA.

$\mathrm{Na}$ criação do $\mathrm{OA}$, foram realizadas reuniões com dois especialistas em conteúdo e dois designers pedagógicos instrucionais. Neste momento houve a proposta e a concepção da ideia central, como também foi feita a elaboração das telas iniciais (Storyboards). Ainda na Fase 1 é realizada, de forma simultânea, a elaboração das Storyboards, telas existentes no OA, e a Implementação. Nessas etapas acontecem constantes interações entre a equipe de elaboração do OA, assim mantém-se um controle do que está sendo produzido e o que foi proposto na etapa de concepção.

Ao realizar a criação e o roteiro das primeiras telas entra em cena outro personagem, os webdesigners. Muitas vezes o Designer Instrucional faz esse papel. Essa elaboração das telas, ou melhor, storyboards, exige do designer uma compreensão e atributos extras em programação e desenvolvimento de materiais educacionais digitais interativos, ou seja, o designer deve deter conhecimentos técnicos em programação e em criação de animações gráficas dependendo do público ao qual o OA será direcionado.

Após essa etapa, entra-se na Fase 2, momento de se enviar os documentos para a equipe técnica de programação para se produzir o OA. Aqui permanece a equipe técnica, e como falado anteriormente, muitas vezes esse papel fica a cargo do Webdesigner. A equipe técnica produz e implementa o OA, sempre consultando o Design Pedagógico Instrucional e aos Webdesigners.

Na etapa de documentação, são elaboradas diretrizes e guias na forma de orientações de utilização pelos especialistas em conteúdos e técnicos em educação, bem como é produzido um roteiro de atividades a serem realizadas utilizando o OA. Ainda na Fase 2, aplica-se o OA em situações de aprendizagem, ou seja, em uma situação problema identificado em sala, para em seguida ser validado.

O OA foi desenvolvido para plataforma Web, programado nas linguagens HTML, CSS e Javascript. Utiliza também JQuery, um framework para Javascript, e um plug-in, o Calculator. Serão apresentadas algumas figuras para melhor entendimento de sua estrutura e utilização.

O software online possui poucas telas, como mostra a Figura 2, o que facilita a organização e entendimento de como o site está organizado. Possui uma tela de início que liga outras três telas: Créditos, Saiba Mais e Iniciar, que por sua vez agrega mais duas outras: as telas de cálculo e a tabela formada a partir das equações da página de cálculo. Nesse caso, o mapa também serve para facilitar os mecanismos de busca a encontrar determinado conteúdo de forma mais prática e rápida. No geral, essa abordagem torna a navegação mais objetiva aos usuários.

Como é possível observar na Figura 3, os componentes que fazem parte do sistema constam de uma página principal escrita em linguagem HTML, em inglês HyperText Markup Language, a folha de estilo, ou Cascading Style Sheet (CSS), e de plug-ins. A programação de eventos e funções foi feita com Javascript. As animações de transição foram feitas utilizando um framework para a linguagem mencionada, JQuery. Além de todos os recursos já citados, ainda foi usado um plug-in chamado Calculator, responsável pela calculadora que o estudante dispõe como auxílio para fazer as contas.

A escolha desses componentes e da plataforma WEB para desenvolver o objeto de aprendizagem OA Tabelando ocorreu por dois motivos: primeiro porque sendo uma página online, pode ser acessada de qualquer ambiente, desde que o usuário disponha de conexão com a Internet; segundo por causa da facilidade do acesso e da comodidade de não haver a necessidade de 


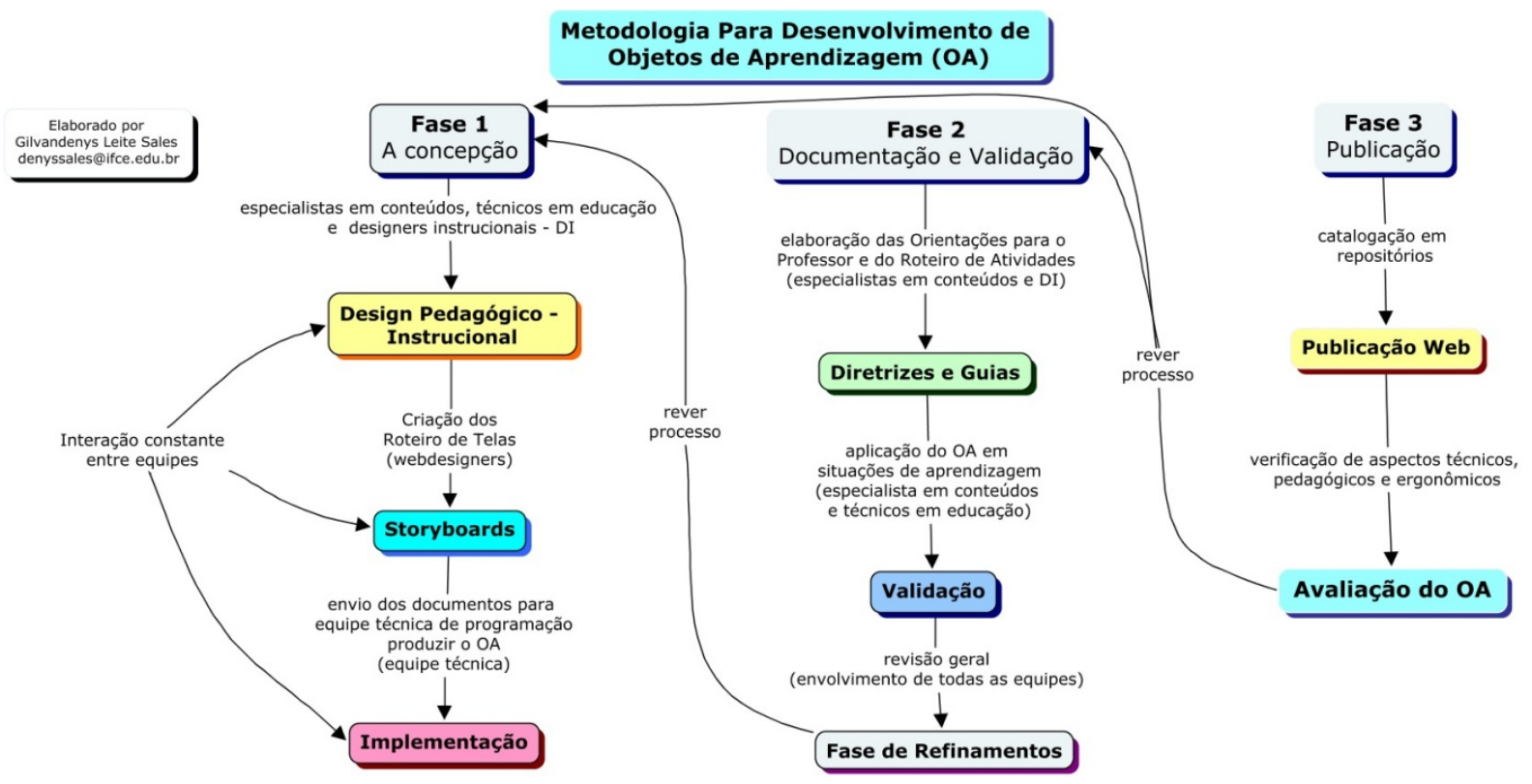

Figura 1: Metodologia de desenvolvimento de Objetos de Aprendizagem.

Fonte: Sales 2012,

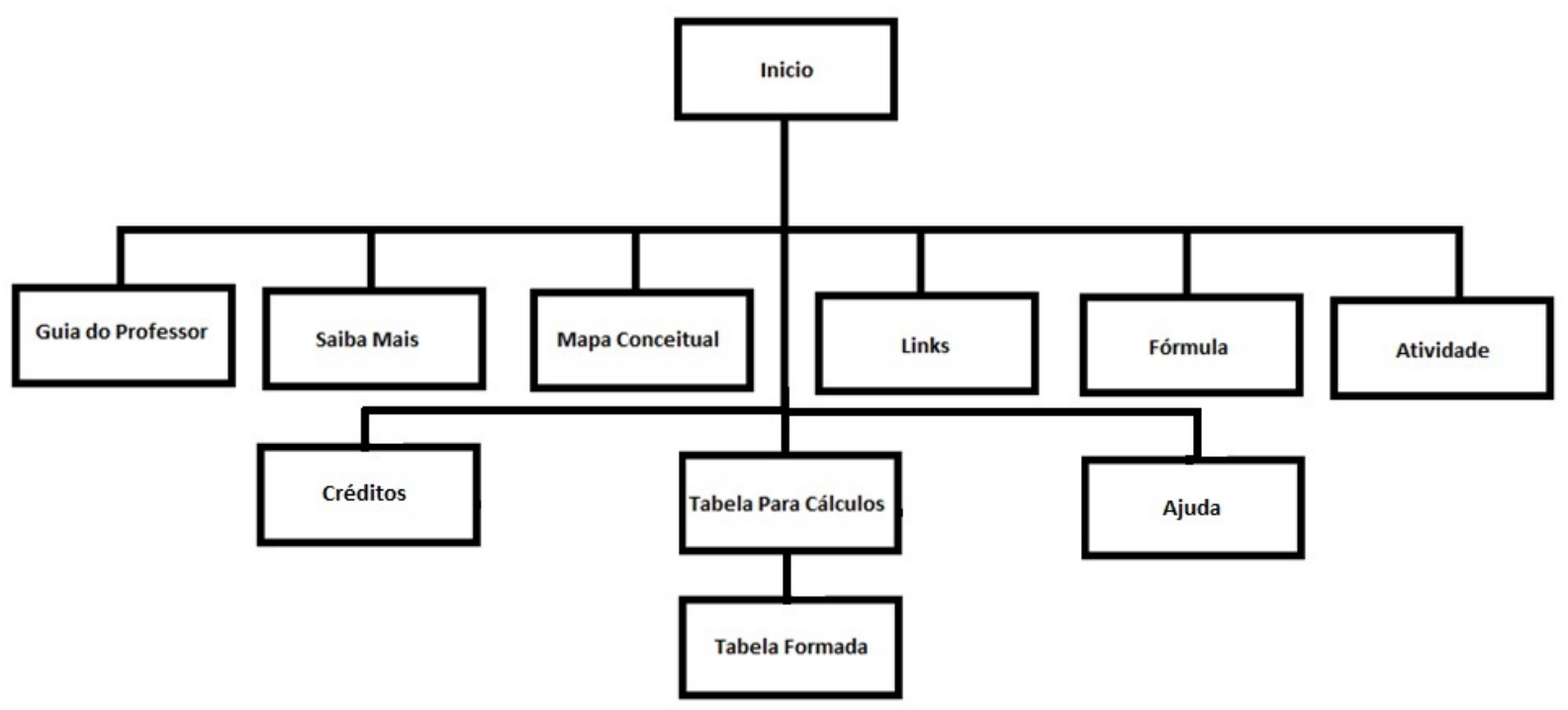

Figura 2: Mapa do site.

Fonte: Pereira 2015, 


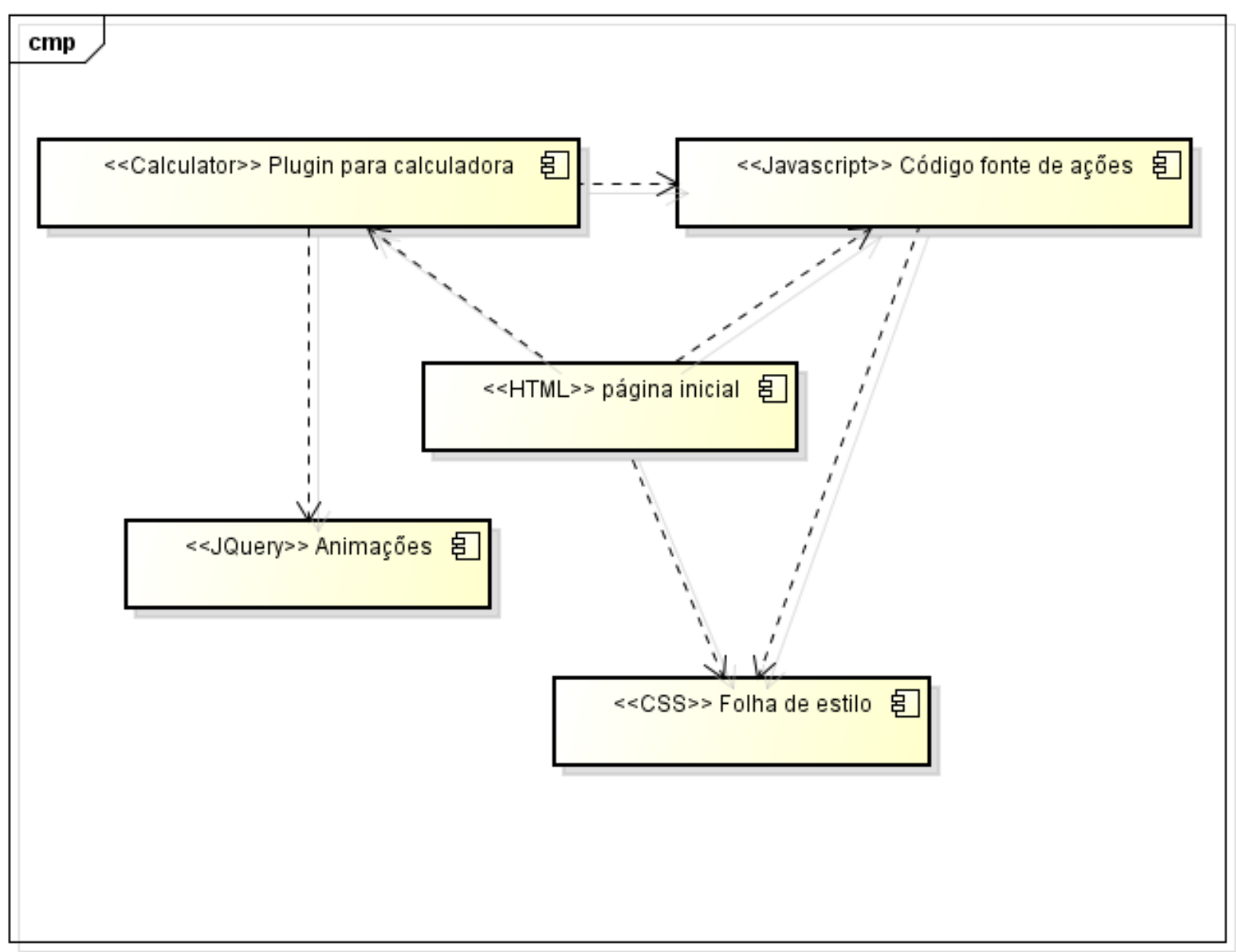

Figura 3: Diagrama de componentes.

Fonte: Pereira 2015, 
instalar no aparelho ou computador. Além disso, o objeto é responsivo, ou seja, adequa-se ao tamanho da tela do dispositivo que está usando para visualizá-lo.

A interação ocorre da seguinte forma: após o professor escolher uma variável para estudo, amostra e tamanho da amostra, os alunos deverão fazer uma pesquisa de campo para coletar as informações da variável escolhida para início.

Nas telas iniciais o aluno deve informar o tamanho da amostra, e em seguida, seguindo as instruções do aplicativo, deverá calcular a Amplitude total dos dados, o número de classes e Amplitude da classe.Após essas informações a TDF (Tabela de Distribuição de Frequência) ganha seu esqueleto, faltando apenas complementar essa tabela seguindo as instruções do OA.

Após completar toda a TDF ele pode verificar o que acertou e o que errou. No caso do erro é indicado onde está o erro. É dada uma pontuação de acordo com o acerto do aluno. Essa pontuação pode ser compartilhada nas redes sociais, gerando uma concorrência sadia entre os alunos. Com a TDF completa o professor pode trabalhar com os alunos as devidas interpretações da tabela.

Na Tela 1 (Figura 4) do Tabelando o aluno pode ter acesso aos arquivos: Guia do Professor, Saiba Mais, Mapa conceitual, Links, Atividade, Fórmulas, Ajuda, Créditos e uma calculadora. No 'Guia do professor' pode-se encontrar todas as informações sobre o OA e informações para auxiliar o professor em sala de aula em relação aos objetivos do OA.No 'Saiba Mais' temse o material complementar sobre Tabela de Distribuição de Frequência com Intervalo de classe. Em 'Mapa Conceitual' pode-se ver representações gráficas semelhantes a diagramas que indicam conceitos relacionados ao assunto abordado no Tabelando.Em 'Links' há indicações de sites relacionados ao tema abordado. Em 'Atividade' pode-se encontrar o que se pretende com o OA. Em 'Fórmulas' tem-se um resumo de fórmulas.

Na Tela 1 e nas demais telas do Tabelando ainda há uma calculadora para que o aluno possa usar nos cálculos; há o botão 'Ajuda', que dará auxílio na utilização do OA e 'Crédito' onde se possa visualizar todos os idealizadores do Tabelando.O aluno pode começar a usar o OA digitando seu nome no local indicado e em seguida teclar no botão 'Entrar'. Na Tela 2 (Figura 5) tem-se um avatar, imagem de uma figura humana de mediação, dando as boas-vindas ao aluno, usando o nome que ele digitou na Tela inicial.Para começar o aluno deve clicar no botão 'INICIAR'.

Em seguida, o aluno tem que completar a tabela após fazer todos os cálculos devidos. Sempre que achar necessário ele pode ver as fórmulas para completar a
Tabela no link de 'Ajuda', que está presente em todas as telas. Após completar toda a tabela ele pode verificar o que acertou e o que errou. No caso do erro é indicado onde está o erro. É atribuída uma pontuação de acordo com o acerto do aluno. Essa pontuação pode ser compartilhada nas redes sociais usando o botão 'Compartilhe no Facebook'. A Figura 6 mostra a tela final para preenchimento e verificação da tabela.

\section{AVALIAÇÃO TÉCNICA E PSICOPEDAGÓ- GICA DO OA TABELANDO}

Para garantir que um software educacional e/ou objeto de aprendizagem seja pedagogicamente viável, é necessário avaliá-lo criteriosamente quanto aos aspectos didáticos e psicopedagógicos, bem como que sejam verificados e estabelecidos critérios ergonômicos e técnicos para que a avaliação seja integral.Logo, além de considerar fundamentais a articulação dos conteúdos e seu rigor científico, o software educacional deve ser capaz de mexer com as emoções do usuário. Para tanto é necessário que apresente uma interface amigável, que seja de fácil navegação, que produza motivação e que realmente seduza.

Para uma melhor análise do software OA Tabelando foram entrevistados quatro professores os quais realizaram um teste de satisfação. Nesse teste eles avaliaram o desempenho do OA, e posteriormente teceram comentários. Os professores responderam algumas informações profissionais, tais como: Qual sua formação? Você leciona? Tempo de carreira? Qual sua área de ensino? Nível de ensino? Atuação?

Na primeira pergunta dois deles afirmaram que possuíam graduação em Matemática, e os outros em Física e Engenharia Química. Quando questionados se lecionavam, todos afirmaram positivamente que sim. Com relação ao tempo de magistério, variou de três a vinte anos de carreira docente. $\mathrm{Na}$ área de ensino afirmaram atuar de forma polivalente e um afirmou atuar somente na área de Matemática. Quanto ao nível de ensino todos lecionam no nível superior.

Visto que checklists que utilizam respostas da forma: 'SIM' ou 'NÃO', não transmitem uma fidedigna interpretação das perguntas. Este instrumento está organizado de tal forma a permitir o caráter subjetivo de cada item abordado, ao possibilitar que sejam tecidos comentários relativos a cada indagação.

O checklist a seguir (Tabela 1), está fundamentado em recomendações para avaliação de interfaces humano-computador elencados por (SILVA, 2002), foi desenvolvido para aplicar uma verificação quanto à funcionalidade e a facilidade de utilização do software OA Tabelando. Aqui os critérios focaram no quesito ergo- 


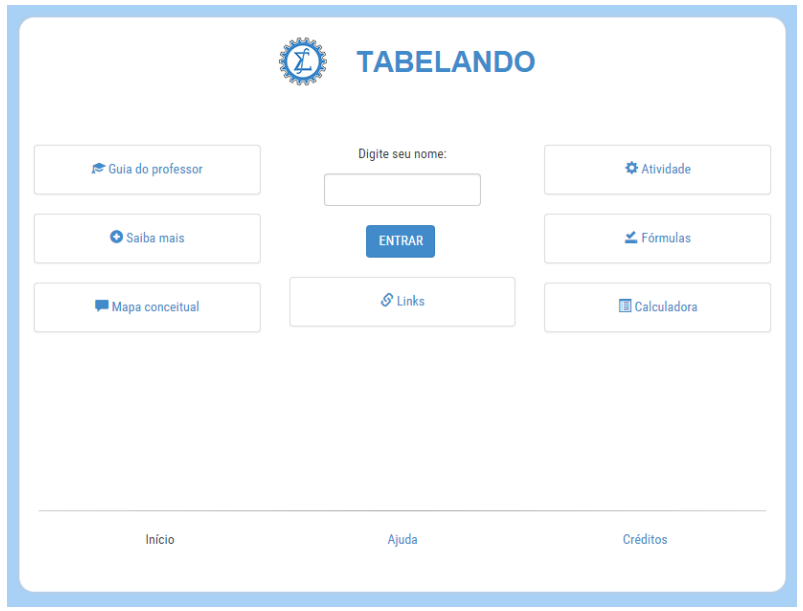

Figura 4: Tela inicial do AO Tabelando.

Fonte: Pereira 2015,

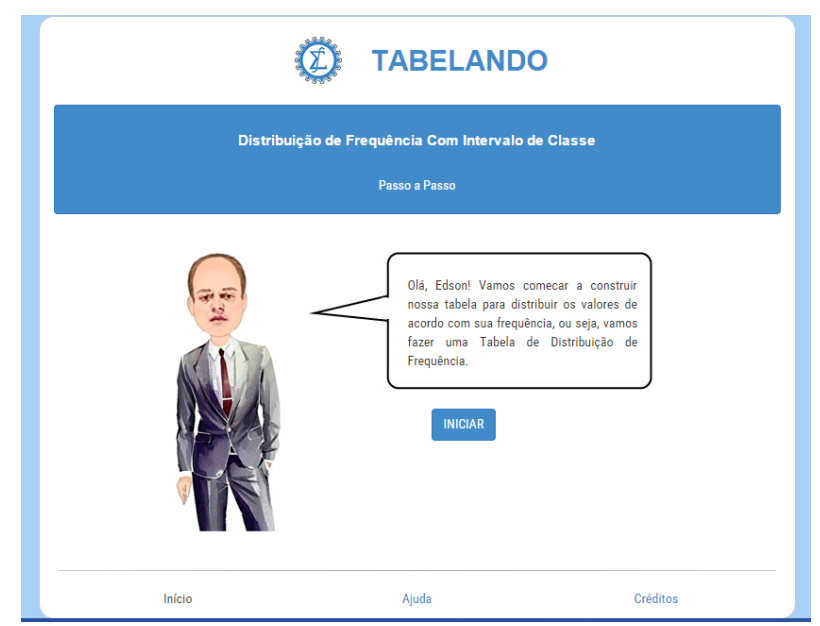

Figura 5: Tela de interação do OA Tabelando.

Fonte: Pereira 2015) 


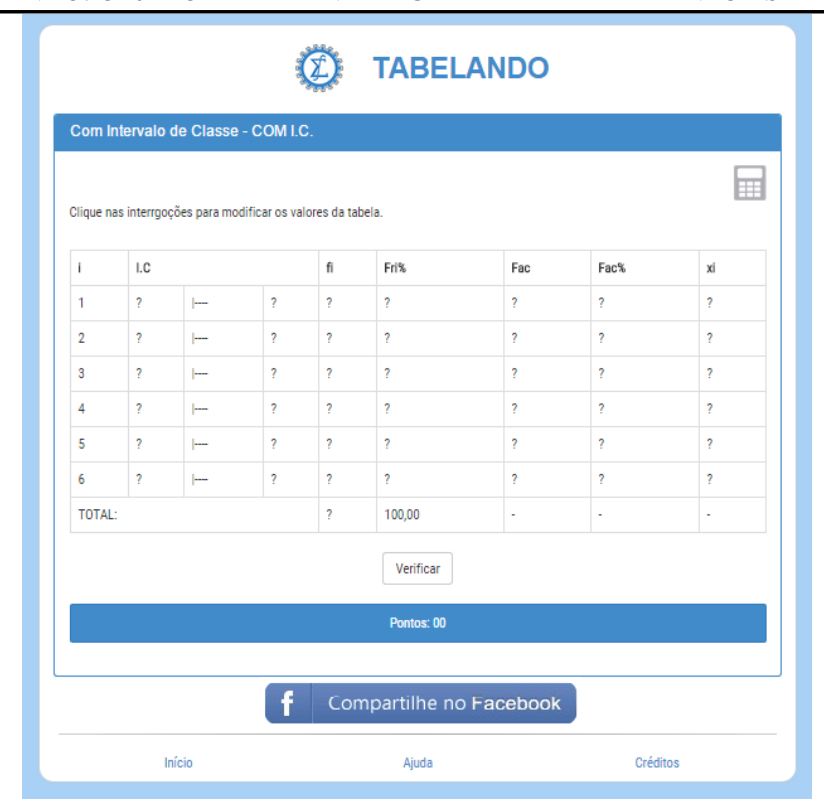

Figura 6: Tela para preenchimento da tabela.

Fonte: Pereira 2015,

nomia, ou seja, o que o software oferece como recursos ou mecanismos para facilitar seu uso. A Tabela 1 possui 21 questionamentos, que ajudam identificar a ausência de algum recurso fundamental ou que possa ser crucial ao professor ao adotar o respectivo software para suas aulas.

Nos comentários, os professores buscaram sugerir como esses erros poderiam ser corrigidos. Como exemplo um dos professores sugeriu na primeira pergunta, onde é solicitado quanto à disponibilização de manuais, contendo instruções com linguagem apropriada, que "Seria interessante se os storyboards fossem disponibilizados como forma de apoio". Nesse comentário, identificam-se contribuições relevantes para buscar melhorias no OA proposto.

Para analisar o Objeto de Aprendizagem OA Tabelando, o mesmo foi aplicado em uma turma de 15 alunos da disciplina de Estatística Aplicada à Administração de uma IES (Instituição de Ensino Superior) na cidade de Fortaleza/CE.

Todas essas opiniões serão analisadas e passarão por um processo de viabilização nas modificações do OA. Assim, as próximas versões trarão melhorias e possibilitarão ainda mais aos alunos desenvolverem seu letramento estatístico.

\section{CONCLUSÕES}

Os problemas no ensino da Matemática persistem, apesar dos crescentes esforços realizados por uma parcela de governantes, teóricos, visionários, professores e alunos. Muitos desses esforços foram obtidos graças às mudanças nas leis, decretos, metodologias e outros meios, porém hoje o recurso tecnologia e ferramentas digitais trazem uma melhor e mais eficaz forma de melhoria no ensino de qualquer área do conhecimento.

Uma das áreas complexas existentes no campo de ensino da Matemática é o ensino de Estatística mostrado neste trabalho. Buscar formas de tornar o ensino e a aprendizagem de Estatística, um processo mais fácil e dinâmico, e possibilitar um letramento estatístico de qualidade aos alunos é crucial.

E por que não utilizar-se das possibilidades que as TDIC (Tecnologias Digitais da Informação e Comunicação) oferecem atualmente como suporte ao ensino e à aprendizagem, utilizando-a para tentar modificar as ações tradicionais e enraizadas no ensino de Matemática?

Ao propor a utilização de uma ferramenta digital, que possibilite novos recursos e mudanças no processo de ensino e aprendizagem, como o Objeto de Aprendizagem OA TABELANDO, este trabalho buscou exatamente responder a estes anseios.

Assim ele foi desenvolvido para apoiar o ensino e 
Tabela 1: Critérios Técnicos/Ergonômicos

\section{QUESTIONAMENTOS}

1. Disponibiliza manual de instrução com linguagem apropriada?

2. Utiliza recursos visuais como relógio, ampulheta ou outros que orientem ao usuário os resultados de suas ações?

3. Fornece ajuda sobre o que o usuário pode fazer na eventual situação em que se encontra sobre o resultado das ações efetuadas?

4. Existem recursos visuais ou sonoros
que orientem ao usuário como navegar?

\section{Disponibiliza um menu que orienta} adequadamente a interface usuário/Objeto de Aprendizagem?

6. Há eficácia na utilização dos recursos para atingir os objetivos a que ele se propõe? 7. O sistema utiliza a linguagem dos usuários de tal maneira que as informações aparecem em uma ordem natural e lógica, em conformidade com palavras, expressões e convenções usuais?

8. Há organização dos menus numa estrutura coerente, de acordo com o conjunto de convenções de interface?

\begin{tabular}{|c|c|c|}
\hline $\begin{array}{l}\text { 9. A navegação é fácil e funcional dentro } \\
\text { do sistema de menus? }\end{array}$ & 4 & "Possibilitar mais o uso do teclado" \\
\hline $\begin{array}{l}\text { 10. Há facilidade para selecionar e executar } \\
\text { as opções de menu? }\end{array}$ & 4 & "Possibilitar mais o uso do teclado" \\
\hline $\begin{array}{l}\text { 11. Há utilização do teclado ou mouse para } \\
\text { navegar nas diversas opções de menus? }\end{array}$ & 4 & "Possibilitar mais o uso do teclado"; "Pelo mouse" \\
\hline $\begin{array}{l}\text { 12. O sistema oferece feedback ao usuário de } \\
\text { forma rápida, com informações sobre a } \\
\text { operação efetuada? }\end{array}$ & 3 & $\begin{array}{l}\text { "Feedback somente quando o aluno realiza a verificação. } \\
\text { O OA somente informa onde está havendo erro" } \\
\text { "Colocar mensagens de incentivo" }\end{array}$ \\
\hline 13. Há diferentes modos para cumprir uma tarefa? & 4 & Não manifestaram comentários \\
\hline 14. O usuário tem controle sobre o sistema? & 4 & Não manifestaram comentários \\
\hline $\begin{array}{l}\text { 15. As informações estão bem distribuídas } \\
\text { na tela e evitam "poluição visual?" }\end{array}$ & 4 & Não manifestaram comentários \\
\hline 16. O software é de fácil instalação e desinstalação? & 4 & "Não precisa instalar". \\
\hline $\begin{array}{l}\text { 17. O sistema oferece boas mensagens e } \\
\text { instruções compreensíveis para os erros cometidos } \\
\text { pelos usuários? }\end{array}$ & 4 & $\begin{array}{l}\text { "Tem no ajuda as instruções, mas falta boas mensagens de erro" } \\
\text { "Colocar mensagens de incentivo" }\end{array}$ \\
\hline
\end{tabular}

18. A interface averigua os erros cometidos pelos usuários? 19. Há consistência e padronização no software? 20. O software é compatível com as características ou perfil do usuário? 4 Não manifestaram comentários 21. A apresentação das informações é clara, bem redigida e livre de equívocos conceituais?
SIM NÃO COMENTÁRIOS

"Existe os recursos visuais, porém efeitos sonoros não" "Somente identifiquei os recursos Visuais"

"Poderia combinar a pontuação com o tempo de execução" "Melhorar e deixar claro como são dadas as pontuações"

Não manifestaram comentários

"Senti falta dos recursos sonoros"

"Existe os recursos visuais, porém efeitos sonoros não" "Somente identifiquei os recursos Visuais"

$4 \quad$ Não manifestaram comentários

4 Não manifestaram comentários

4 "Somente identifiquei os recursos Visuais"

4 Não manifestaram comentários

Não manifestaram comentários Não manifestaram comentários

4

4

Não manifestaram comentários

Não manifestaram comentários 
Tabela 2: Avaliação dos alunos

\begin{tabular}{|c|c|c|c|}
\hline Aluno & Nome do Aluno & Críticas/Elogios & Sugestões \\
\hline 1 & Aluno 1 & Possibilidade de retorno sem perda de informação já inserida & Destacar mais a pontuação final ou mudar a tela dando a nota. \\
\hline Resposta: & & Estudo da possibilidade & Estudo da possibilidade \\
\hline 2 & Aluno 2 & $\begin{array}{l}\text { O programa é bastante interessante podendo ser } \\
\text { utilizado na disciplina de Estatística. }\end{array}$ & $\begin{array}{l}\text { Ficaria melhor se puder ser feito todos os cálculos necessários. } \\
\text { Por exemplo, ele não fez o cálculo da amplitude total, bem como } \\
\text { os demais cálculos. O aluno entrando com os dados e o programa } \\
\text { desenvolveria os cálculos. Claro que as fórmulas seriam dadas em } \\
\text { sala de aula para o entendimento dos alunos. }\end{array}$ \\
\hline Resposta: & & & $\begin{array}{l}\text { A ideia do OA é que o aluno faça os cálculos necessários. O OA } \\
\text { deve ensinar a técnica do processo, mas cabe ao aluno fazer todos } \\
\text { os cálculos necessários. }\end{array}$ \\
\hline 3 & Aluno 3 & Não calcular sozinho. & Calcular sozinho. \\
\hline Resposta: & & & $\begin{array}{l}\text { A ideia do OA é que o aluno faça os cálculos necessários. O OA } \\
\text { deve ensinar a técnica do processo, mas cabe ao aluno fazer todos } \\
\text { os cálculos necessários. }\end{array}$ \\
\hline 4 & Aluno 4 & "Processo de inserir/completar a tabela muito cansativo." & $\begin{array}{l}\text { Os campos "?"poderiam ser substituídas pelas fórmulas de ajuda. } \\
\text { O aluno pudesse ser inserir/editado com o uso de "Tab"ao invés } \\
\text { de usar o mouse, mesmo para as teclas de seta, que nessa versão } \\
\text { não tem funcionalidade }\end{array}$ \\
\hline Resposta: & & Estudo da possibilidade & Estudo da possibilidade \\
\hline $\mathrm{r}$ - & Aluno 5 & "Dá muito trabalho colocar as informações." & $\begin{array}{l}\text { 1. Poderia usar a tecla "Tab". 2. Ter a opção acima para colocar a } \\
\text { sequência de números. }\end{array}$ \\
\hline Resposta: & & Estudo da possibilidade & $\begin{array}{l}\text { 1. Estudo da possibilidade2. Como cabe o aluno fazer a contagem, a } \\
\text { opção de colocar os valores não se torno necessários. }\end{array}$ \\
\hline 6 & Aluno 6 & $\begin{array}{l}\text { 1. Não completa com números quebrado. } \\
\text { 2. Se voltar, apaga tudo, eu voltei (reiniciei } 8 \text { vezes) }\end{array}$ & Trabalhar com valores quebrados. \\
\hline Resposta: & & $\begin{array}{l}\text { Relevante. 1. Problema está sendo corrigido. } \\
\text { 2. Estudo da possibilidade }\end{array}$ & Problema está sendo corrigido. \\
\hline 7 & Aluno 7 & $\begin{array}{l}\text { O aplicativo está bem estruturado, mas tem pequenos defeitos } \\
\text { quando voltar a tabela, ela apaga toda a tabela. }\end{array}$ & Poder voltar sem ter que começar do zero. \\
\hline Resposta: & & Estudo da possibilidade & Estudo da possibilidade \\
\hline 8 & Aluno 8 & $\begin{array}{l}\text { É muito simples, pois somente preenche a tabela de acordo } \\
\text { com os dados fornecidos. Aplicando-se as fórmulas que } \\
\text { estão no campo de ajuda para ser consultada. }\end{array}$ & $\begin{array}{l}\text { Poderia ser acrescentada as fórmulas já na tabela, substitui-se } \\
\text { somente os valores para chegar no resultado. }\end{array}$ \\
\hline Resposta: & & & Estudo da possibilidade \\
\hline 9 & Aluno 9 & $\begin{array}{l}\text { O programa é bem melhor do que fazer em sala, pois quando } \\
\text { a gente termina a tabela já fala o que tá certo e o que tá errado. }\end{array}$ & Gravar as notas dos alunos \\
\hline Resposta: & & & Estudo da possibilidade \\
\hline 10 & Aluno 10 & Muito bom, facilita o aprendizado. & Imprimir a Tabela ou salvar em pdf ou como imagem. \\
\hline Resposta: & & & Estudo da possibilidade \\
\hline 11 & Aluno 11 & Aplicativo muito versátil, prático, facilitando o aprendizado. & \\
\hline 12 & Aluno 12 & $\begin{array}{l}\text { O aplicativo na plataforma Web é muito bom, pois ajuda os } \\
\text { alunos a compreender melhor a distribuição de frequência e } \\
\text { a construção da Tabela. O aplicativo mostra passo a passo } \\
\text { como fazer cada cálculo o que é outro ponto positivo. }\end{array}$ & Deveria aceitar número com vírgula. \\
\hline Resposta: & & & Problema está sendo corrigido. \\
\hline 13 & Aluno 13 & $\begin{array}{l}\text { A plataforma é interessante, entretanto apresentou problemas } \\
\text { em relação aos números decimais. O Design está bom, e no } \\
\text { total é interessante. }\end{array}$ & $\begin{array}{l}\text { O mais, na minha opinião, seria muito bom um app, que uma } \\
\text { vez posto os dados, a plataforma efetuasse todos os cálculos }\end{array}$ \\
\hline Resposta: & & Problema está sendo corrigido. & $\begin{array}{l}\text { A ideia do OA é que o aluno faça os cálculos necessários. } \\
\text { O OA deve ensinar a técnica do processo, mas cabe ao aluno } \\
\text { fazer todos os cálculos necessários. }\end{array}$ \\
\hline 14 & Aluno 14 & $\begin{array}{l}\text { O aplicativo "Tabelando"apresenta um excelente formato, } \\
\text { em relação a tabela de distribuição de frequência, e é de } \\
\text { fácil compreensão. Porém, apresenta alguns defeitos, como } \\
\text { por exemplo, a verificação dos dados decimais. }\end{array}$ & $\begin{array}{l}\text { Melhorar a calculadora, pois apresenta poucos dígitos deixando-a } \\
\text { limitada a outras ações. }\end{array}$ \\
\hline Resposta: & & Problema está sendo corrigido. & Estudo da possibilidade \\
\hline 15 & Aluno 15 & $\begin{array}{l}\text { Muito bom! Ganho de aprendizagem muito maior } \\
\text { do que na sala de aula. }\end{array}$ & \\
\hline
\end{tabular}


a aprendizagem de Estatística com uma proposta pedagógica que facilita a compreensão de conceitos e a interpretação de tabelas estatísticas, possibilitando um Letramento Estatístico de qualidade ao aluno.

Com base no apanhado teórico realizado foi possível identificar que muitos autores buscam realizar as mudanças acima mencionadas propondo soluções que facilitem todo o processo de aprendizagem matemática. Muitos trouxeram propostas similares à do presente trabalho, trazendo outras ferramentas digitais, que facilitasse a aprendizagem. Também foi visto que muitas destas propostas estão disponíveis nos diversos repositórios digitais de ferramentas educacionais existentes.

Outra etapa importante observada foi o processo de idealização, modelagem, prototipação, análise de possibilidades, engenharia de software, design pedagógico entre outras etapas no desenvolvimento do OA TABELANDO, momento em que os desenvolvedores se depararam com dificuldades em encontrar uma proposta simples e de fácil acesso e compreensão de alunos e professores.

Também foi possível obter conclusões em torno da implementação após o OA ter sido desenvolvido e testado. Solicitar a opinião de profissionais da área para avaliarem o funcionamento do OA, ajudou a identificar os erros ou ausência de funcionalidades. Sem essas colocações o OA TABELANDO não evoluiria e consequentemente não corresponderia às expectativas esperadas.

Com o desenvolvimento do OA foram obtidos resultados esclarecedores por meio das atividades da pesquisa que delinearam a contribuição apresentada neste trabalho, como se pode identificar ao se revisitar os objetivos específicos traçados aqui.

Ao implementar o Objeto de Aprendizagem como um exemplo prático de atividade estatística, foram obtidas as opiniões e críticas que possibilitaram efetuar mudanças consideráveis no projeto do OA TABELANDO.

Encontrou-se baixo quantitativo de ferramentas e de objetos educacionais com foco em Estatística, e em assuntos específicos como a Distribuição de Frequência.

Outros empecilhos encontrados foram: o desempenho dos alunos está muito aquém do esperado em muitos dos assuntos abordados na Matemática; o despreparo do professor em utilizar-se de ferramentas informacionais em suas aulas; a falta de incentivo por parte das escolas que insistem em manter o currículo e a metodologia tradicional e o desconhecimento da existência dos repositórios de OA.

O OA TABELANDO veio propor soluções para muitos desses pontos, uma vez que durante sua aplicação em salas de aula na resolução de situações pro- blema, pode possibilitar a melhoria e o desempenho dos alunos ao realizarem suas atividades.

Outro ponto a ser destacado neste trabalho foi a aplicação do instrumento de avaliação a professores e alunos, pois eles contribuíram com sugestões e críticas plausíveis de serem realizadas como refinamentos do OA TABELANDO.

Com os dados obtidos nas atividades realizadas pelos alunos observaram-se mudanças no empenho, na dedicação, e isso refletiu positivamente na aprendizagem dos mesmos. Assim percebeu-se que, pelos comentários em sala e outros registrados nas tabelas, que o uso do OA TABELANDO tem influência significativa na motivação desses alunos, estimula a pratica de pesquisa, facilita a construção da Tabela de Distribuição de Frequências, que com a intervenção do professor, tornase de fácil análise e interpretação.

A aprendizagem significativa promovida pelo OA TABELANDO é uma experiência pedagógica bem mais produtiva, que permite aos aprendizes adquirirem novos conhecimentos, possibilitando-lhes interpretar os dados estatísticos e utilizá-los como ferramenta de conhecimento da realidade social.

Com o presente trabalho espera-se criar novos métodos para se ensinar estatística utilizando e consequentemente promovendo uma aprendizagem significativa aproveitando ao máximo os recursos tecnológicos existentes. E que este OA contribua significativamente e positivamente no processo de aprendizagem. Espera-se também que novos estudos sejam realizados utilizando o OA TABELANDO, e que estes busquem contribuir também de forma positiva no processo de Letramento Estatístico de muitos alunos.

Como sugestão para trabalhos futuros o presente trabalho propõe melhorias no OA, que o mesmo seja aperfeiçoado e possibilite trabalhar gráficos, ou mesmo, incentive o desenvolvimento de outros OA que atuem exclusivamente nessa questão.

\section{REFERÊNCIAS}

ALMEIDA, C. C. D. Análise de um instrumento de letramento estatístico para o ensino fundamental II. São Paulo: , 2010.

BRASIL. Lei de diretrizes e bases da educação:(Lei 9.394/96). Brasília, DF: DP \& A, 1996.

BRASIL, R. C. e. C. Resolução ceb n ${ }^{\circ} 03$. DIRETRIZES OPERACIONAIS PARA A EDUCAÇÃO BÁSICA NAS ESCOLAS DO CAMPO. Ministério da Educação, Brasília, DF, junho 1998. 
BRASIL, S. d. E. F. Parâmetros curriculares nacionais: matemática. Brasília, DF: , 1997.

BRIGNOL, S. M. S. Novas tecnologias de informação e comunicação nas relações de aprendizagem da estatística no ensino médio. Faculdade Jorge Amado-Especialização em Educação Estatística com ênfase em Softwares Estatísticos. Salvador, BA, 2004.

CAZORLA, I. M.; SANTANA, E. Do tratamento da informação ao letramento estatístico. Itabuna: Via Litterarum, 2010.

GAL. 2002. 2004.

HOFFMAN. 2007.

PEREIRA, E. do C. Tabelando: objeto de aprendizagem para facilitar o letramento estatístico. Fortaleza, Ceará: , 2015.

RUMSEY. 2002.

SALES, G. L. Como fazer OA? Uma Metodologia para desenvolver Objetos de Aprendizagem. 2012. Disponível em: <http://professordenyssales.blogspot.com.br/ 2012/02/como-fazer-oa-uma-metodologia-para.html> [Acesso em: 5 jun. 2015].

SILVA, C. Oliveira e. MAEP: um método ergopedagógico interativo de avaliação para produtos educacionais informatizados. Tese (Doutorado) $\mathrm{PhD}$ Dissertation, Federal University of Santa Catarina. Florianópolis: UFSC, 2002. [Acesso em: $10 \mathrm{dez}$. 2016].

SILVA, E. L. da; CAFÉ, L.; CATAPAN, A. H. Os objetos educacionais, os metadados e os repositórios na sociedade da informação. Ciência da Informação, v. 39, n. 3, 2011. [Acesso em: 13 abr. 2015].

SOARES, M. Letramento: um tema em três gêneros. belo horizonte: Autêntica, 2003b. _. Linguagem e escola: uma perspectiva social, v. 2, 2002.

VYGOTSKY, L. S. A formação social da mente. São Paulo, v. 3, 1984. 